Www.jmscr.igmpublication.org

Impact Factor (SJIF): 6.379

Index Copernicus Value: 79.54

ISSN (e)-2347-176x ISSN (p) 2455-0450

crossrefDOI: https://dx.doi.org/10.18535/jmscr/v6i8.201

Journal Of Medical Science And Clinical Research

IGM Publication

An official Publication of IGM Publication

\title{
Functional Outcome of Intra-Articular Fractures of the Distal Humerus Treated with Open Reduction and Internal Fixation with Distal Humeral Locking Plates and Screws
}

Authors

\author{
Dr Vikaas Ethanur Thuppale ${ }^{1 *}$, Dr Madan Mohan ${ }^{2}$
}

Kerala Institute of Medical Sciences, Trivandrum, Kerala - 695029, India

*Corresponding Author

Dr Vikaas Ethanur Thuppale

Residence address: Plot. No. 2, First street, Sri Ayappa Nagar, Kolathur, Chennai-600099

Work address: Resident, Department of Orthopaedics, Kerala Institute of Medical

Sciences, Trivandrum, Kerala - 695029, India

Contact No-9840677242, Email: vikaaset@gmail.com

\begin{abstract}
We have assessed the functional outcome in patients who were treated with open reduction and internal fixation with anatomical locking plates and screws for intra-articular fractures of the distal Humerus. Data was collected using a pre-tested questionnaire on personal information and data pertaining to injury and followed up at intervals of 6 weeks, 3 months and 6 months. The Mayo Elbow performance Score (MEPS) was used to assess the functional outcome. At the end of 6 months, none had poor functional outcomes, $3.4 \%$ (1 patient) had a fair functional outcome, 34.5\% (10 patients) had good outcomes and 62.1\% (18 patients) had excellent functional outcomes. The final outcomes of our study indicated that anatomical locking plate fixation is a good option in the management of intra-articular distal Humerus fractures.

Keywords: Distal Humerus, intra-articular fracture, Mayo elbow performance score, functional outcome.
\end{abstract}

\section{Background and Aim}

Fractures of the distal humerus remain a challenging problem despite advances in technique and implants. Rarely is a "normal" elbow the outcome after these fractures, but outcomes have been improved with advances in implant technology, surgical approaches, and rehabilitation protocols. The goal of treatment is anatomic restoration of the joint surface with stable internal fixation that allows early motion.

Our aim was to evaluate and analyze the functional outcome associated with intra-articular fractures of the distal Humerus treated by open reduction and internal fixation with distal humeral locking plates and screws.

\section{Materials and Methods}

The study was conducted at a tertiary health care centre from $1^{\text {st }}$ March, 2016 to $1^{\text {st }}$ December, 2017 where 29 patients with intra-articular fracture distal humerus were selected for study. Data was collected using a pre-tested questionnaire on personal information and data pertaining to injury (time, cause, type of injury, site of injury, 
associated soft tissue injuries) during the study period. Mechanism of injury, amount of articular involvement and comminution, amount of soft tissue damage, general condition of the patient, associated medical illness, occupation of the patient, time to surgery and other associated injuries in a polytraumatized patient were noted.

Anatomical reduction and rigid internal fixation is considered the gold standard for most displaced intra-articular distal humerus fractures (AO/OTA types $\mathrm{B}$ and $\mathrm{C}$ ). In cases where sufficient fracture stability could not be obtained to allow early motion, anatomic reconstruction of the articular surface and overall elbow alignment took precedence. Anteroposterior and lateral radiographs of the elbow out of plaster were usually sufficient to determine the fracture pattern. If the radiographs were difficult to interpret or poorly demonstrate the articular fracture, a CT scan was preferred, with three-dimensional reconstructions. The fractures were classified based on the AO/OTA system of distal humeral fracture classification depending on the individual fracture patterns.

All the cases in this series were done using the posterior approach using an Olecranon osteotomy. Once the distal humerus articular surface was adequately exposed, the fracture hematoma was evacuated and the raw fracture surfaces were cleaned of loose debris. We preferred K-wires for manipulation and provisional reduction of fracture fragments. A large pointed reduction forceps was used to hold the reduction. Once the provisional articular reduction was obtained with transfixing $\mathrm{K}$-wires, placement of a single $32 \mathrm{~mm}$ partially threaded cancellous screw $(4 \mathrm{~mm})$ along the axis of the articular segment was done to maintain the reduction. Fractures with severe articular comminution required rigid attachment to the medial and lateral columns to the distal humerus shaft. Precontoured plates were then provisionally applied to the medial and lateral columns with Kwires placed distally and serrated bone reduction clamps proximally. Then, as many locking screws $(3.5 \mathrm{~mm})$ as possible were inserted through the plates into the articular segment. Screws were not placed through the olecranon fossa as they would lead to impingement. The plates were then fixated to the humeral shaft with the first diaphyseal screws inserted in an eccentric fashion to provide supracondylar fracture compression.

Once ORIF of the distal humerus fracture was complete, the elbow was placed through a range of motion to ensure there was no impingement or instability. The surgical wound was closed over a suction drain and an above elbow slab was given with the elbow in 90 degree flexion. Some patients were started on active and passive elbow ROM from the $3^{\text {rd }}$ day itself, whereas in some patients, active and passive elbow ROM was started on the 14th postoperative day after the removal of the sutures in view of the fact that longer periods of immobilization resulted in higher incidence of Heterotopic ossification and elbow stiffness.

All patients were followed up at 6 weeks, 3 months and 6 months. Check x rays were taken to assess fracture union and signs of failure of reduction and fixation. Following parameters were assessed:

\section{Functional parameters}

1) Pain (mild/ moderate/ severe)

2) Gross swelling

3) Range of movements (Flexion - extension)

4) Any post-operative persistent complications

\section{Radiological parameters}

1) Degree of varus/valgus deformity, if present (at 6 months)

2) Presence of myositis ossificans (at 6 months)

The primary functional outcome was measured with the help of (MEPS) Mayo elbow performance score ${ }^{1}$.

Total Score 90-100

: Excellent

Total Score 75-89

: Good

Total Score 60-74

: Fair

Total Score Less than 60 


\section{JMSCR Vol||06||Issue ||08||Page 1230-1242||August}

\section{Statistical analysis}

All the data was entered into MS Excel and analyzed using the statistical software SPSS version 22.0. All categorical variables were expressed as in percentages (\%) and continuous variables in mean and standard deviation (S.D), or median with interquartile range. A Chi-Square test was used for comparison of categorical variables and an independent $t$ test. The confidence interval was considered as $95 \%$. A p value $<0.05$ was considered to be statistically significant. Paired comparisons of quantitative variables were analyzed by Wilcoxon Signed Rank Test.
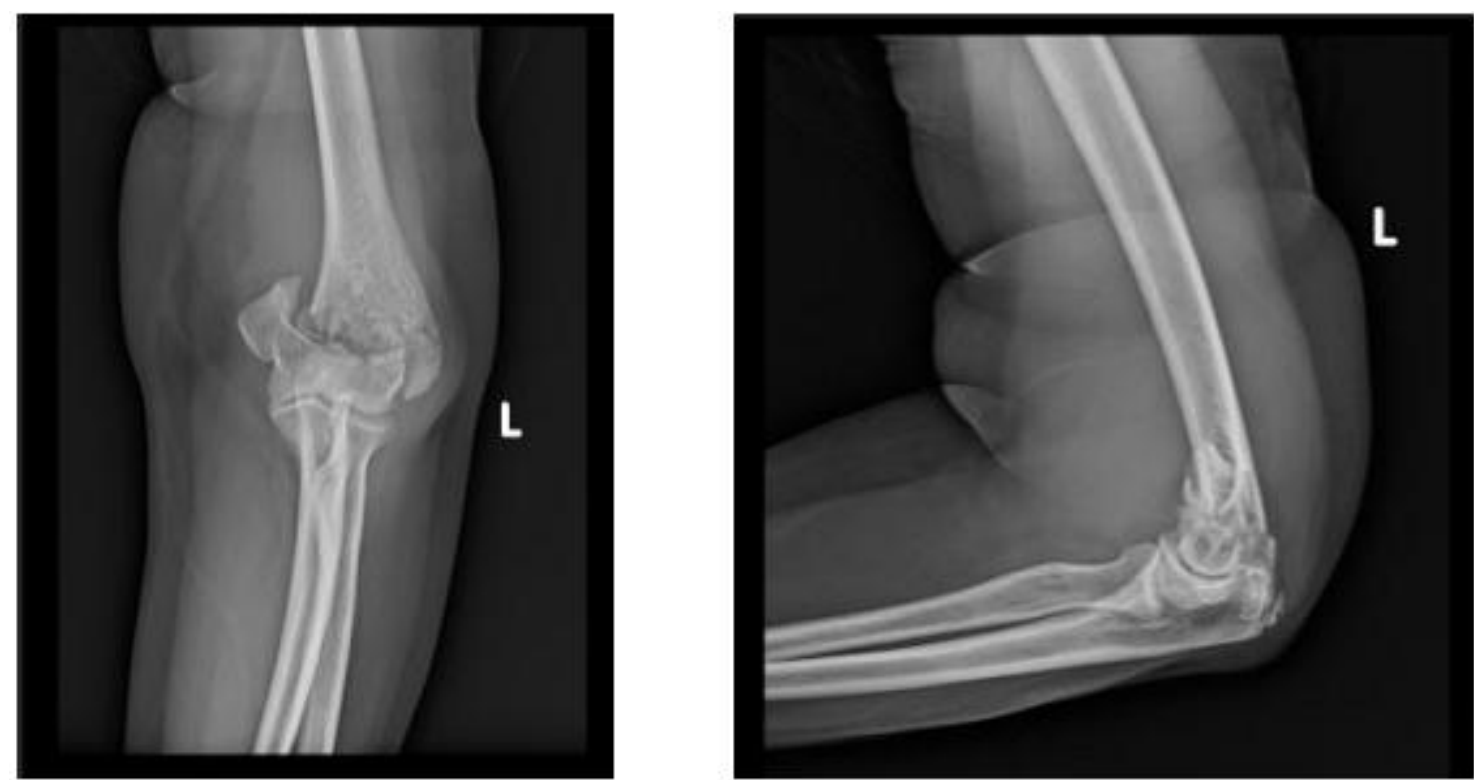

Figure 1- Another patient with an AO type C2 intra-articular fracture
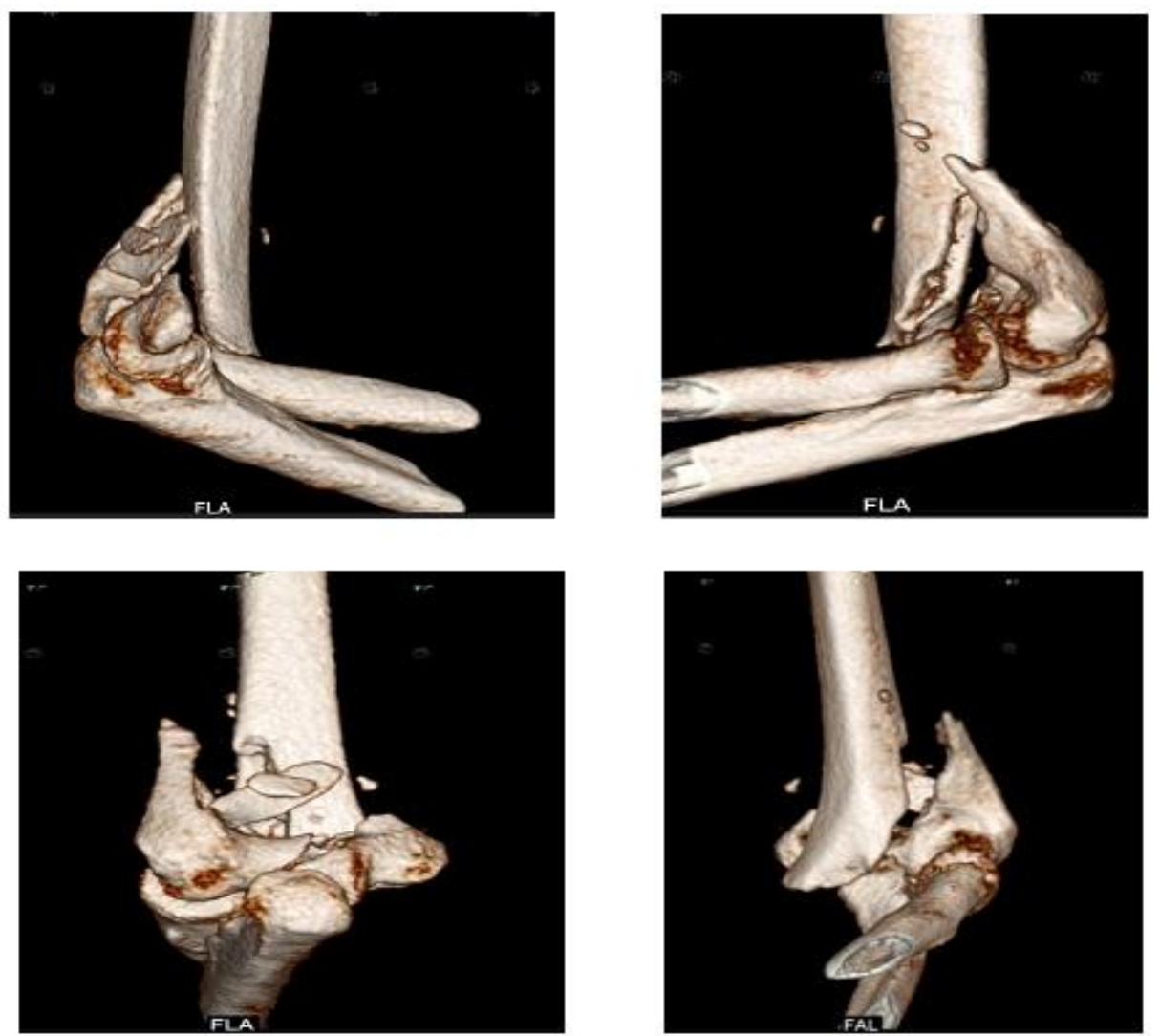

Figure 2 CT 3-D Reconstruction views of an AO type C2 fracture for further evaluation 


\section{JMSCR Vol||06||Issue||08||Page 1230-1242||August}

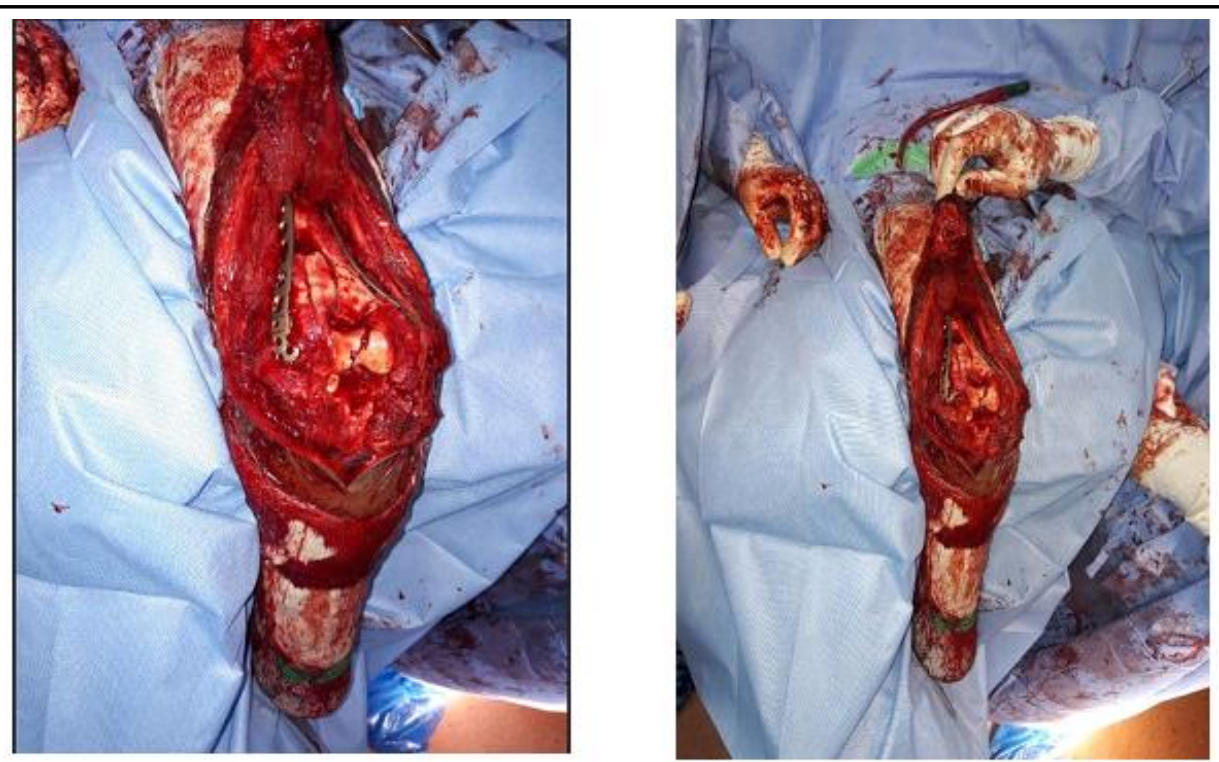

Figure 3 Posterior approach to the distal Humerus with an olecranon osteotomy
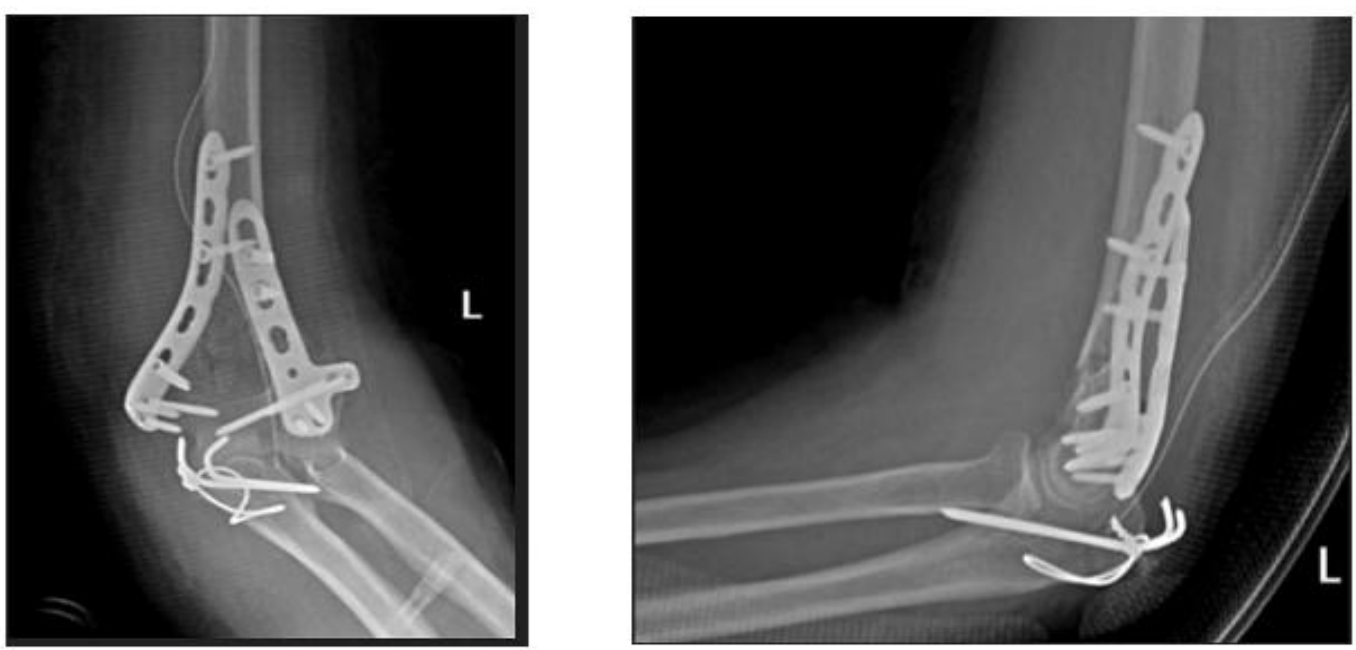

Figure 4 - Post op xray AP \&lat views of AO Type C2 fracture
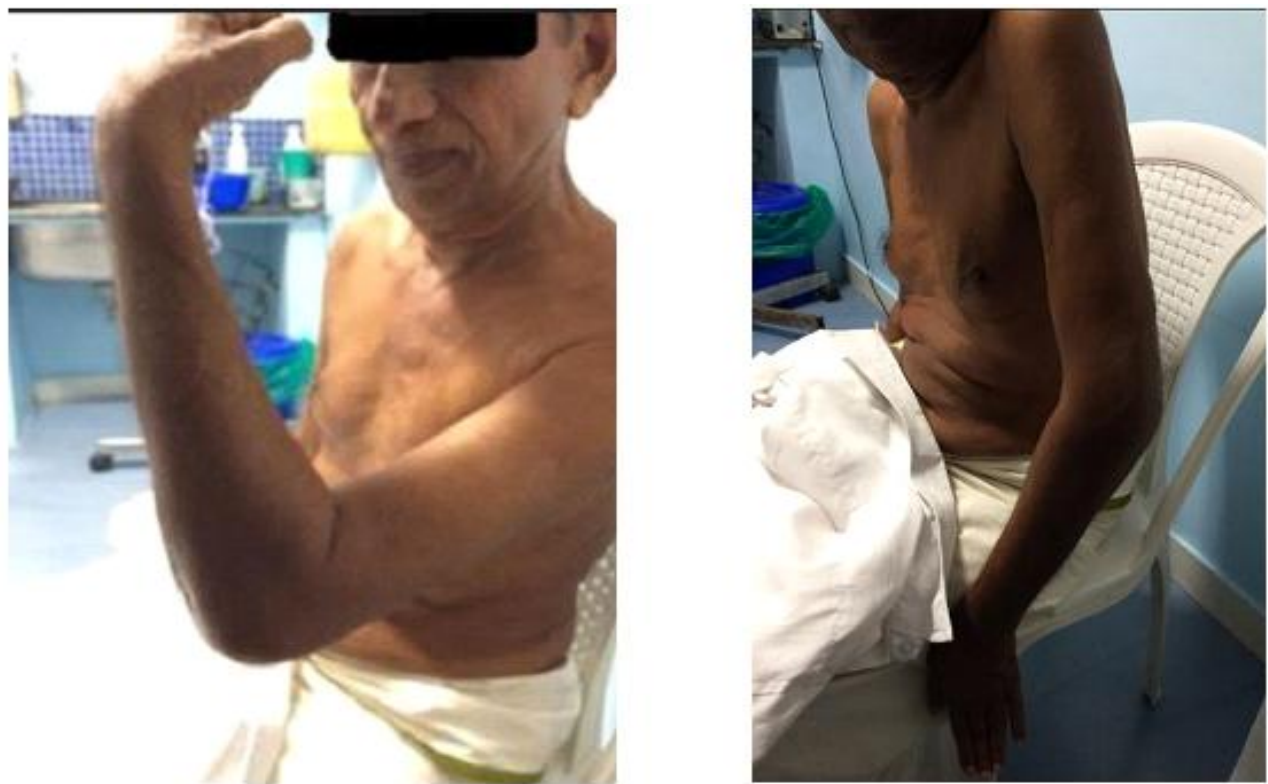

Figure 5 - ROM at 6 weeks 


\section{JMSCR Vol||06||Issue||08||Page 1230-1242||August}
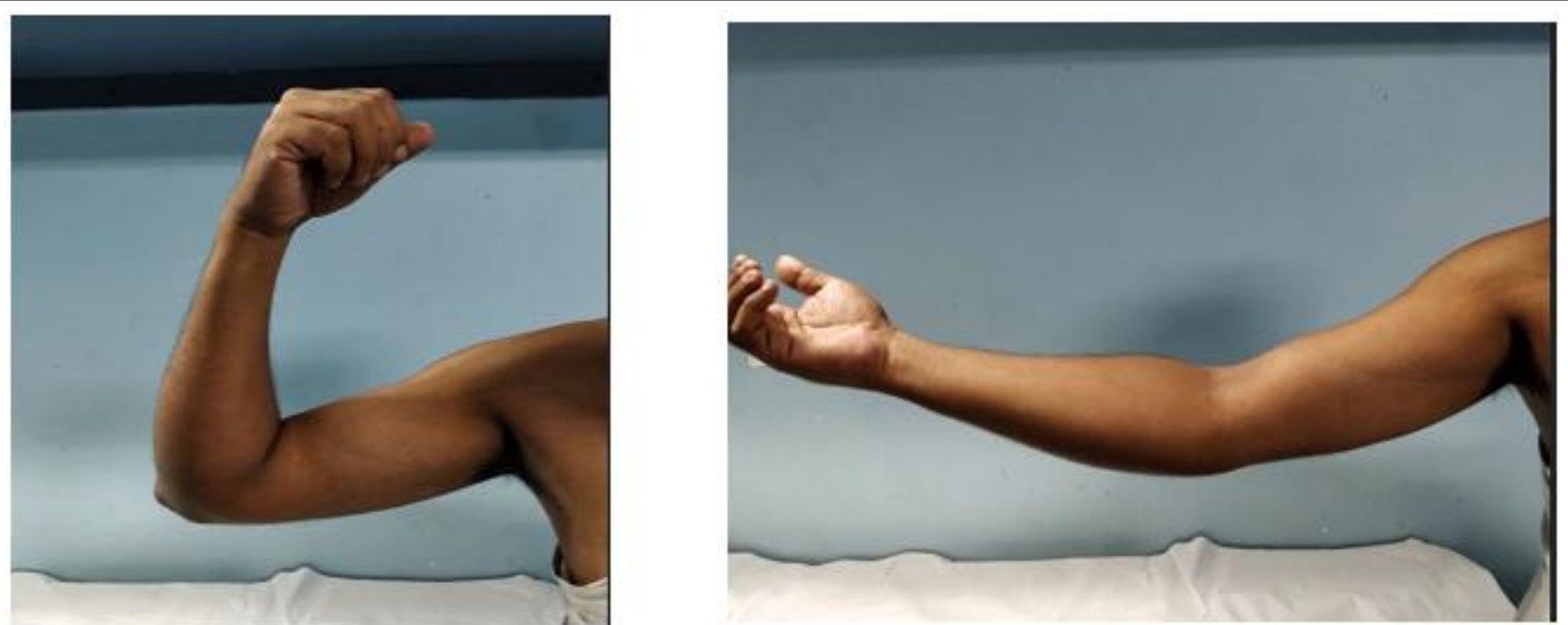

Figure 6 ROM at 3 months
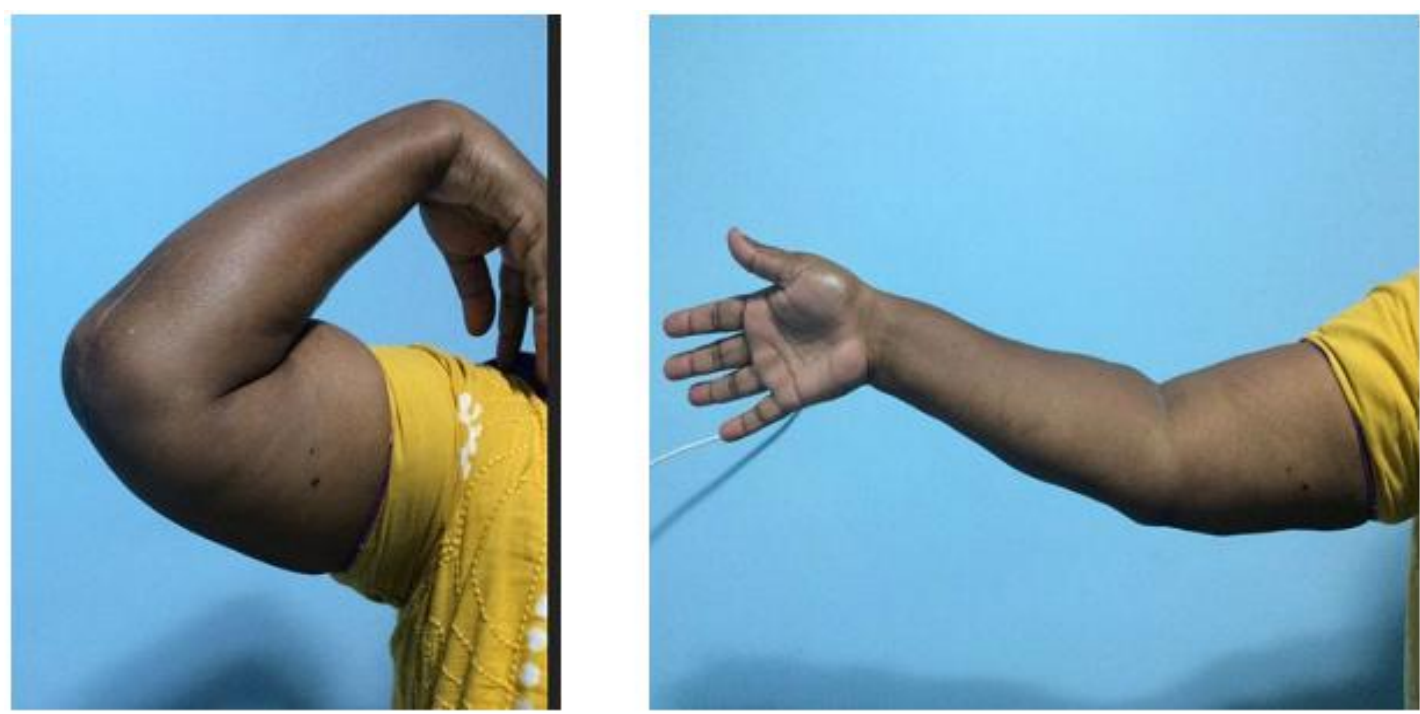

Figure 7 ROM at 6 months

\section{Results}

Age wise distribution

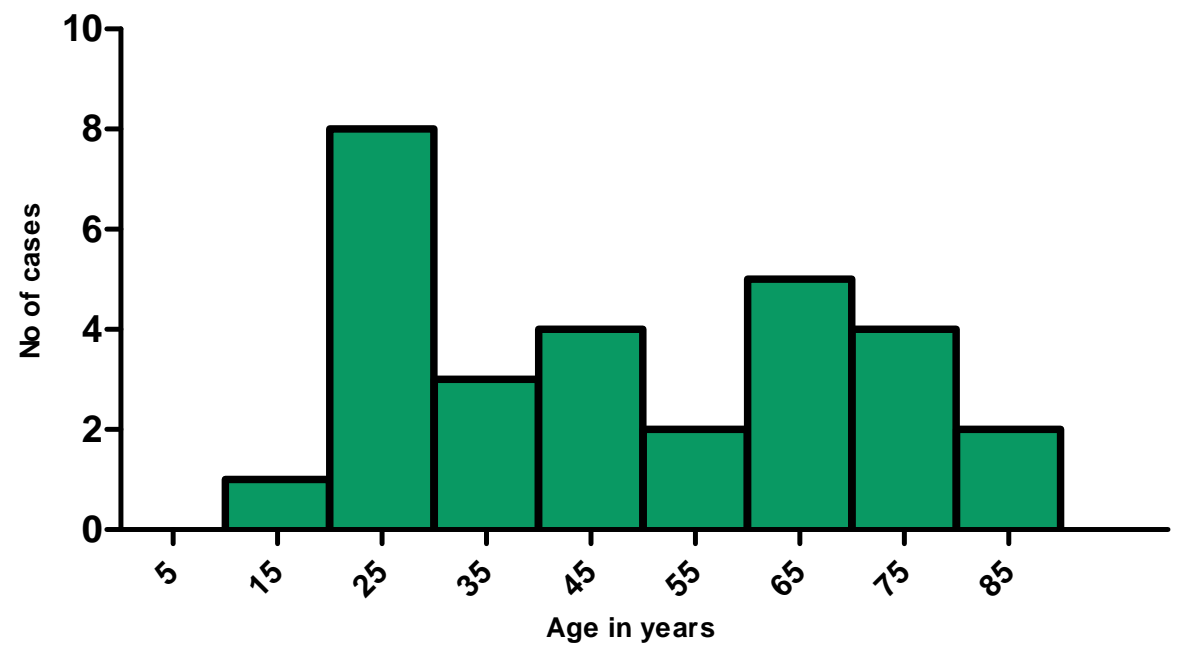

Figure 8 Age wise distribution ( $\mathrm{X}$ axis - Age in years, $\mathrm{Y}$ axis - No. of cases) 


\section{JMSCR Vol||06||Issue||08||Page 1230-1242||August}

Time to surgery

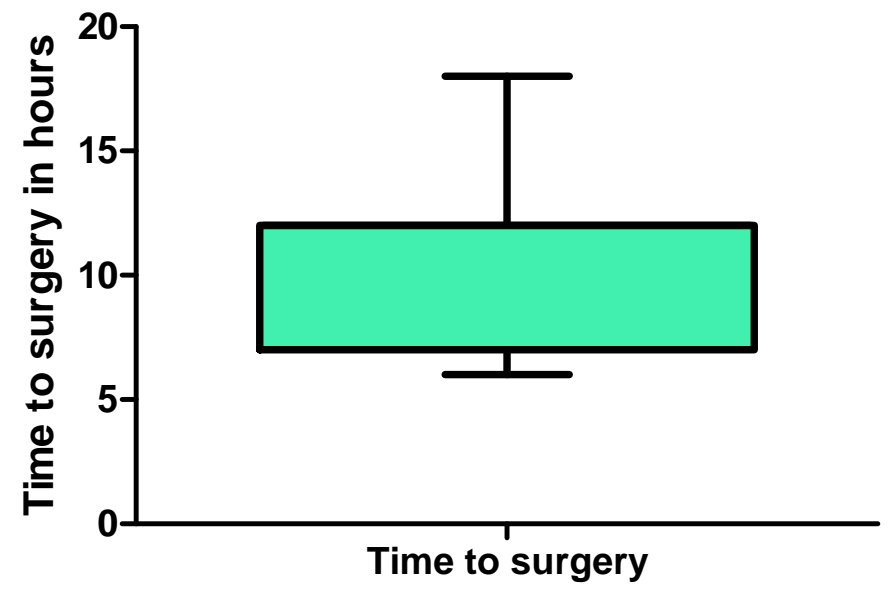

Figure 9 Range depicting the time to surgery (Y axis - Time to surgery in hours)

\section{Gender wise distribution}

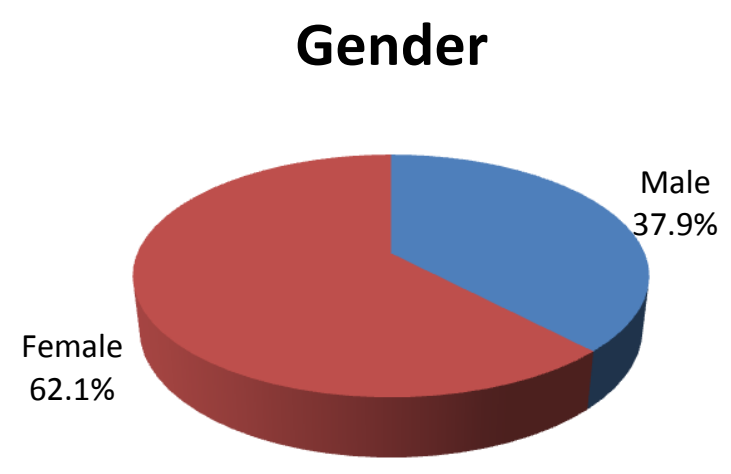

Figure 10 Pie chart showing the gender wise distribution

Mode of injury

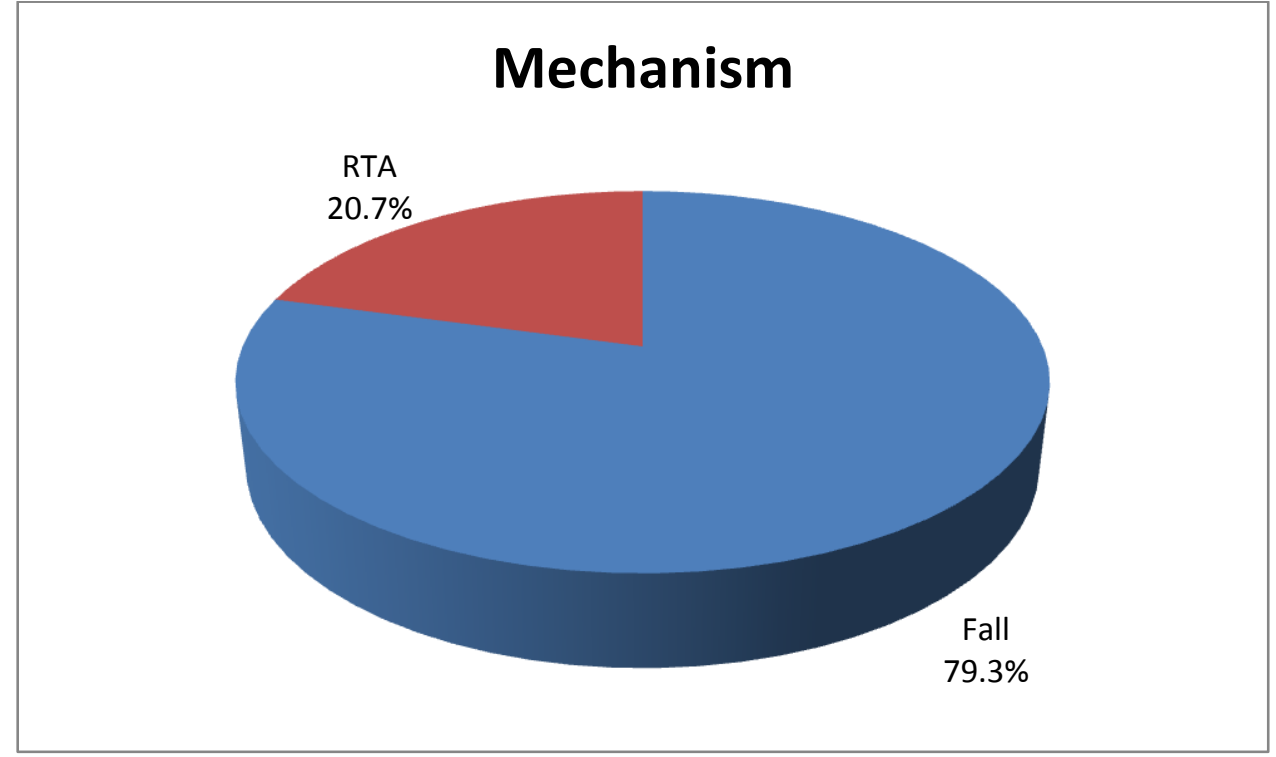

Figure 11 Pie chart showing the different Modes of injury 
AO/OTA type distribution

\begin{tabular}{|l|c|c|}
\hline AO/OTA type & Frequency & Percent \\
\hline 13-A1 & 4 & 13.8 \\
\hline 13-A2 & 4 & 13.8 \\
\hline 13-A3 & 1 & 3.4 \\
\hline 13-B1 & 4 & 13.8 \\
\hline 13-B2 & 2 & 6.9 \\
\hline 13-B3 & 1 & 3.4 \\
\hline 13-C1 & 4 & 13.8 \\
\hline 13-C2 & 6 & 20.7 \\
\hline 13-C3 & 3 & 10.3 \\
\hline Total & 29 & 100.0 \\
\hline
\end{tabular}

Table 1 AO/OTA type distribution

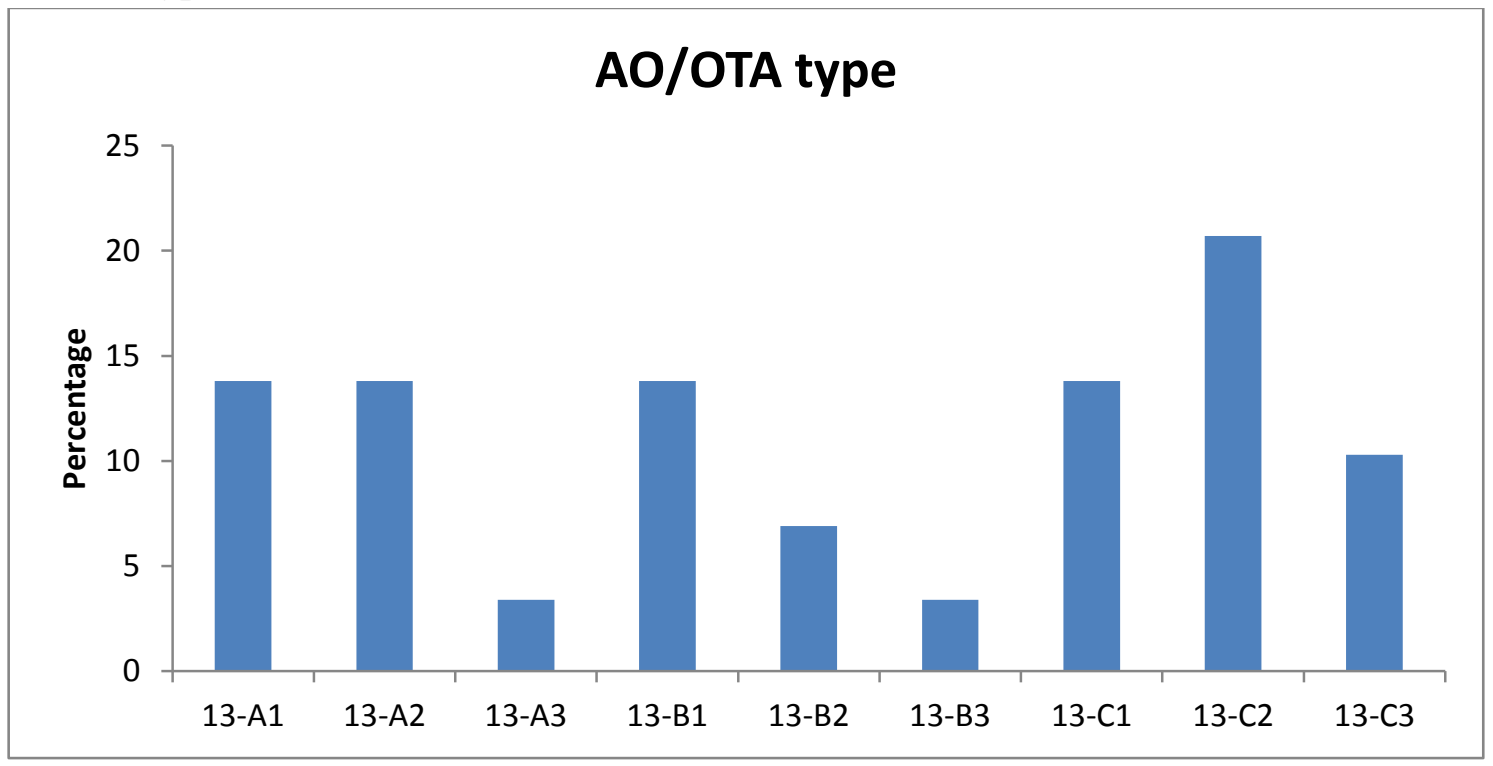

Figure 12 AO/OTA type distribution ( $\mathrm{X}$ axis - AO/OTA type, $\mathrm{Y}$ axis - Percentage of total cases)

Side wise distribution

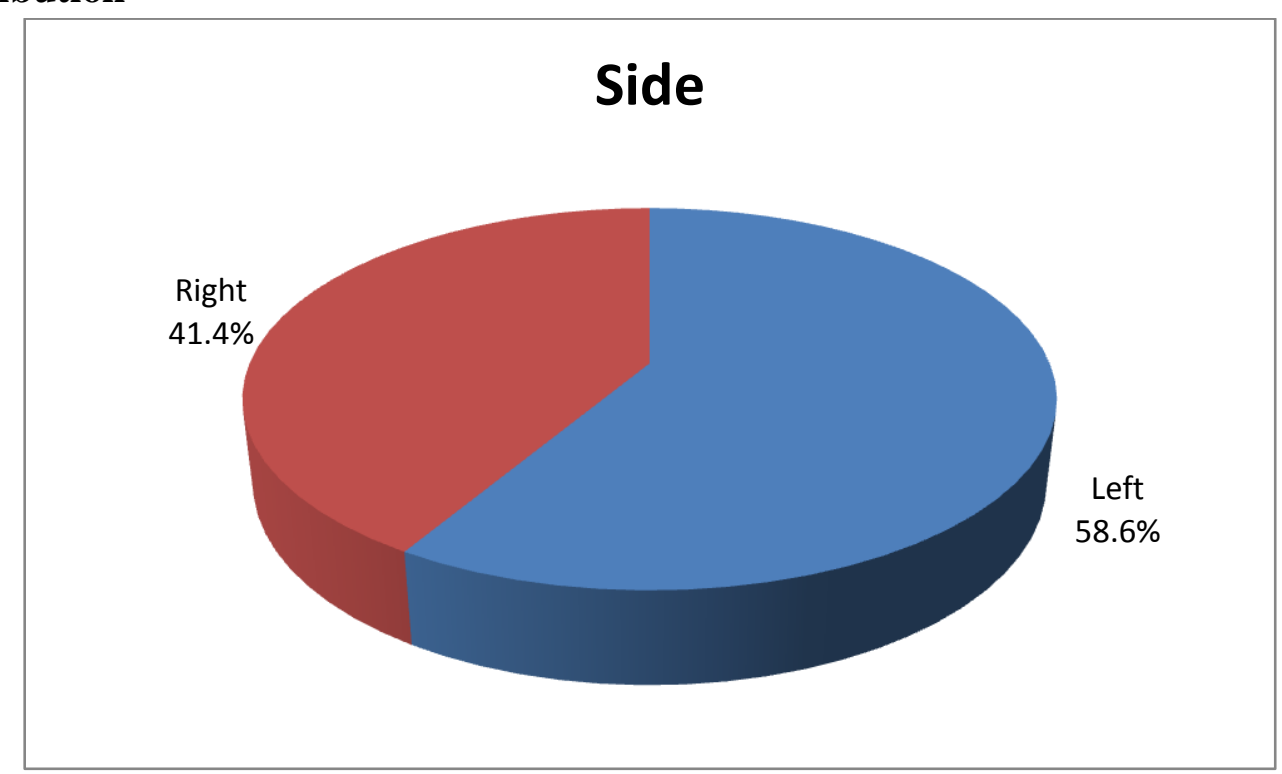

Figure 13 Pie chart showing the side wise distribution 


\section{Associated comorbidities}

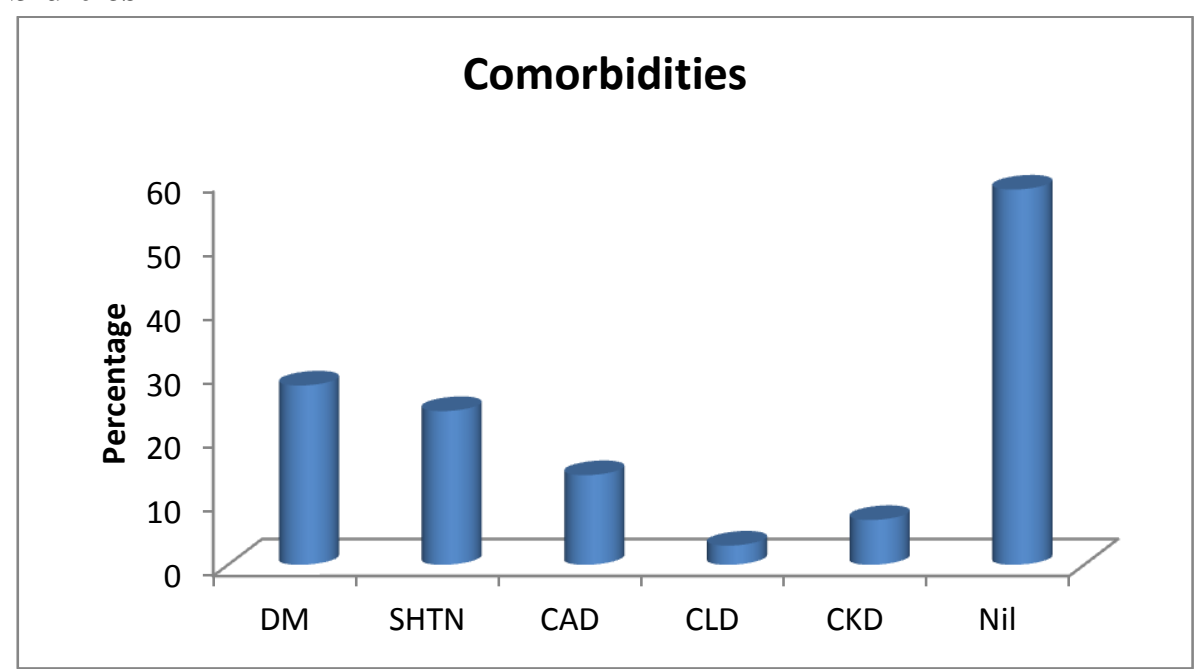

Figure 14 - Associated comorbidities ( $\mathrm{X}$ axis - Various comorbidities, Y axis - Percentage of total cases) *DM-Diabetes Mellitus, SHTN - Systemic Hypertension, CAD - Coronary Artery Disease, CLD - Chronic Liver Disease, CKD - Chronic Kidney Disease

\section{Start of ROM}

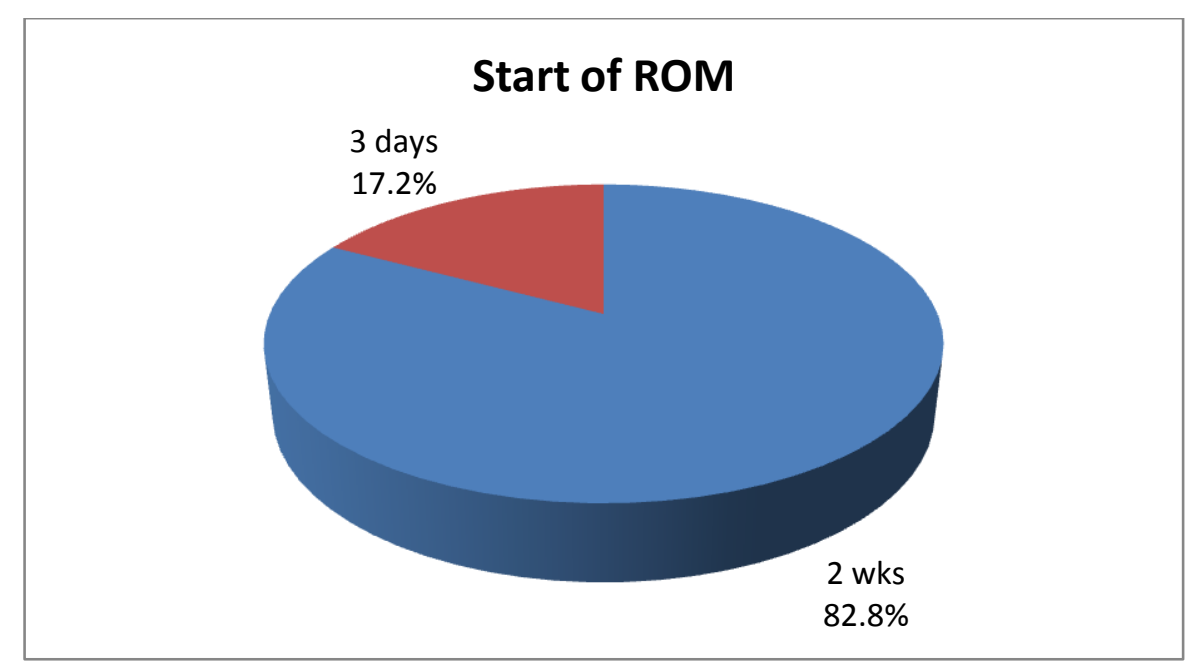

Figure 15 Pie chart showing the time of start of ROM following surgery

\section{Swelling}

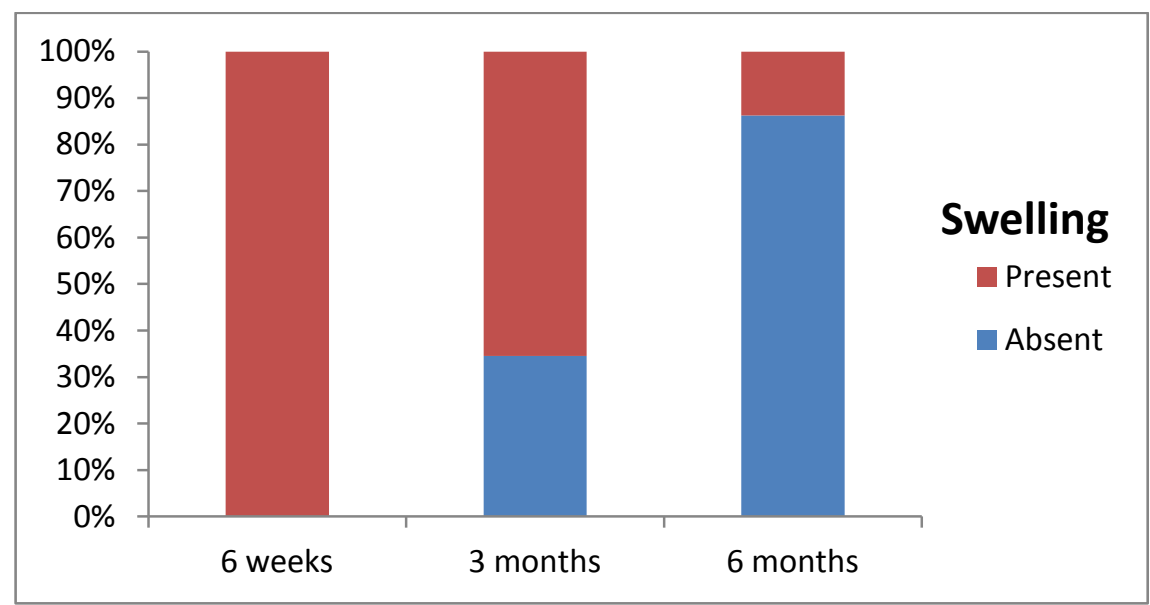

Figure 16 Presence of gross elbow swelling at 6 weeks, 3 months and 6 months (X axis - Time since surgery, Y axis - Percentage of total cases) 


\section{Presence of postoperative complications}

2 patients $(6.9 \%)$ developed surgical site infection within 6 weeks after surgery which was managed by debridement and appropriate antibiotic coverage. 2 patients (6.9\%) developed hardware related complications at 6 months.

Alignment (degree of Valgus degrees) at the end of 6 months

Table 2 Alignment in degrees of Valgus at the end of 6 months

\begin{tabular}{|l|c|c|}
\hline $\begin{array}{l}\text { Alignment in } \\
\text { degrees of valgus }\end{array}$ & Frequency & Percent \\
\hline 3 & 1 & 3.4 \\
\hline 5 & 5 & 17.2 \\
\hline 7 & 3 & 10.3 \\
\hline 9 & 1 & 3.4 \\
\hline 10 & 14 & 48.3 \\
\hline 15 & 5 & 17.2 \\
\hline Total & 29 & 100.0 \\
\hline
\end{tabular}

Range of motion at 6 weeks, 3 months and 6 months

Table 3 ROM at 6 weeks, 3 months and 6 months

\begin{tabular}{|l|c|c|c|c|c|}
\hline \multirow{2}{*}{ Time since surgery } & \multirow{2}{*}{$\mathrm{N}$} & \multicolumn{4}{|c|}{ ROM } \\
\cline { 3 - 6 } & & Mean & $\mathrm{SD}$ & Median & $\begin{array}{c}\text { Interquartile } \\
\text { range }\end{array}$ \\
\hline 6 weeks & 29 & 95.5 & 24.0 & 90.0 & $75.0-120$ \\
\hline 3 months & 29 & 118.6 & 21.3 & 110.0 & $100.0-140$ \\
\hline 6 monhts & 29 & 134.8 & 13.5 & 130.0 & $130.0-150$ \\
\hline
\end{tabular}

\section{ROM}

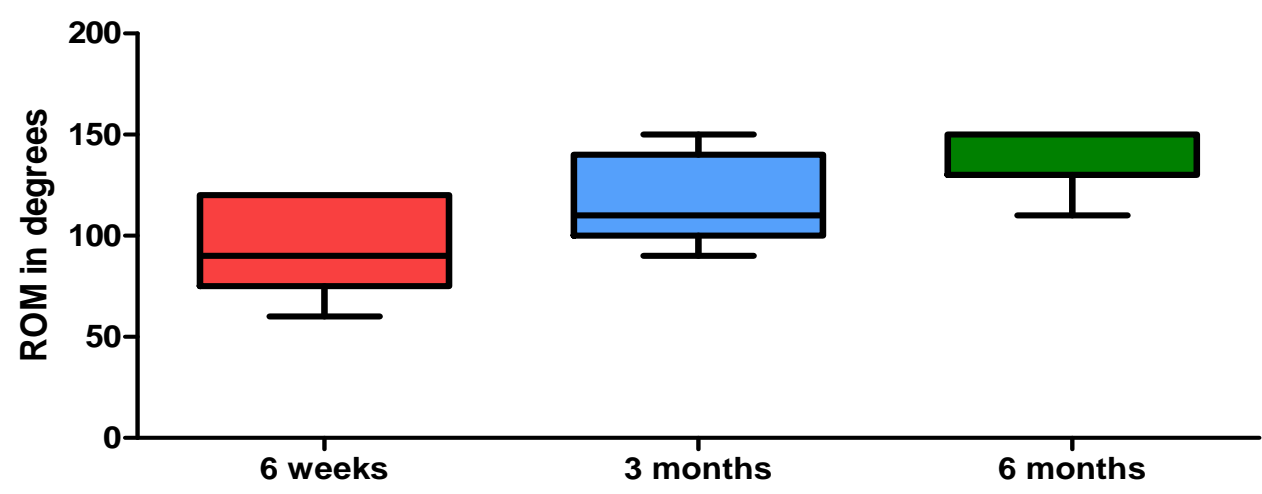

Figure 17 ROM at 6 weeks, 3 months and 6 months ( $\mathrm{X}$ axis - Time since surgery, $\mathrm{Y}$ axis -ROM in degrees)

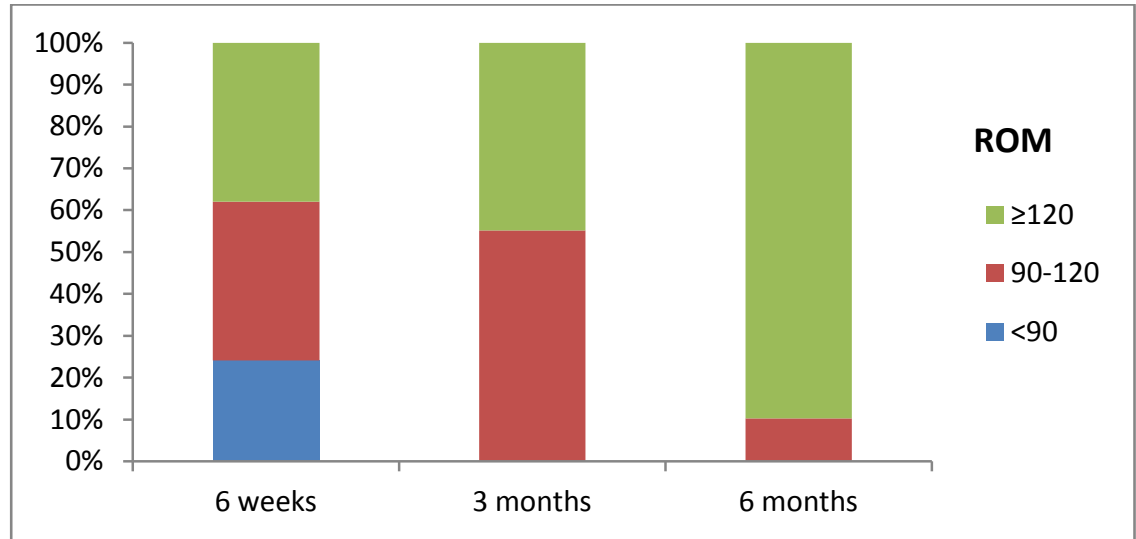

Figure 18 - ROM at 6 weeks, 3 months and 6 months (x axis - Time since surgery, Y-axis - Percentage of total cases) 
Mayo Elbow Performance Score at 6 weeks, 3months and 6 months

Table 4 - Mayo Elbow Performance Score at 6 weeks, 3months and 6 months

\begin{tabular}{|c|c|c|c|c|c|}
\hline \multirow[b]{2}{*}{ Time since surgery } & \multirow[b]{2}{*}{$\mathrm{N}$} & \multicolumn{4}{|c|}{ MEPS } \\
\hline & & Mean & sd & Median & $\begin{array}{l}\text { Interquartile } \\
\text { range }\end{array}$ \\
\hline 6 weeks & 29 & 66.2 & 6.8 & 65.0 & $62.5-70.0$ \\
\hline 3 months & 29 & 77.1 & 6.5 & 80.0 & $75.0-80.0$ \\
\hline 6 monhts & 29 & 87.8 & 8.0 & 90.0 & $80.0-95.0$ \\
\hline
\end{tabular}

$\mathrm{p}<0.001$

\section{MEPS}

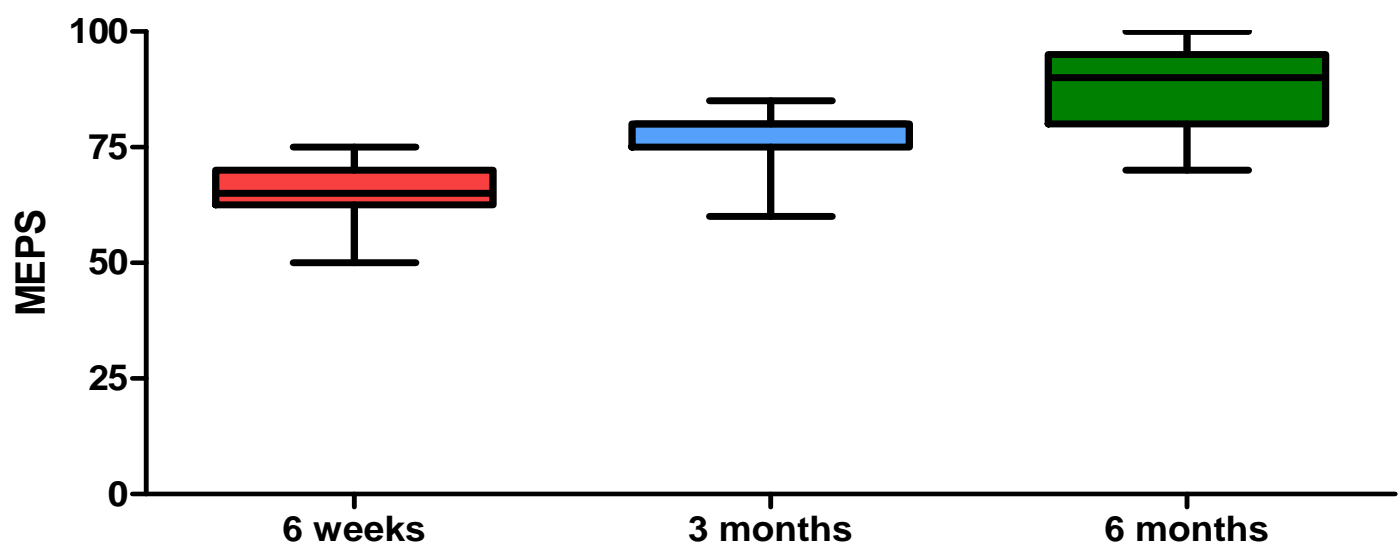

Figure 19 Distribution of MEPS at 6 weeks, 3 months and 6 months (X-axis - Time since surgery, Y-axis MEPS score)

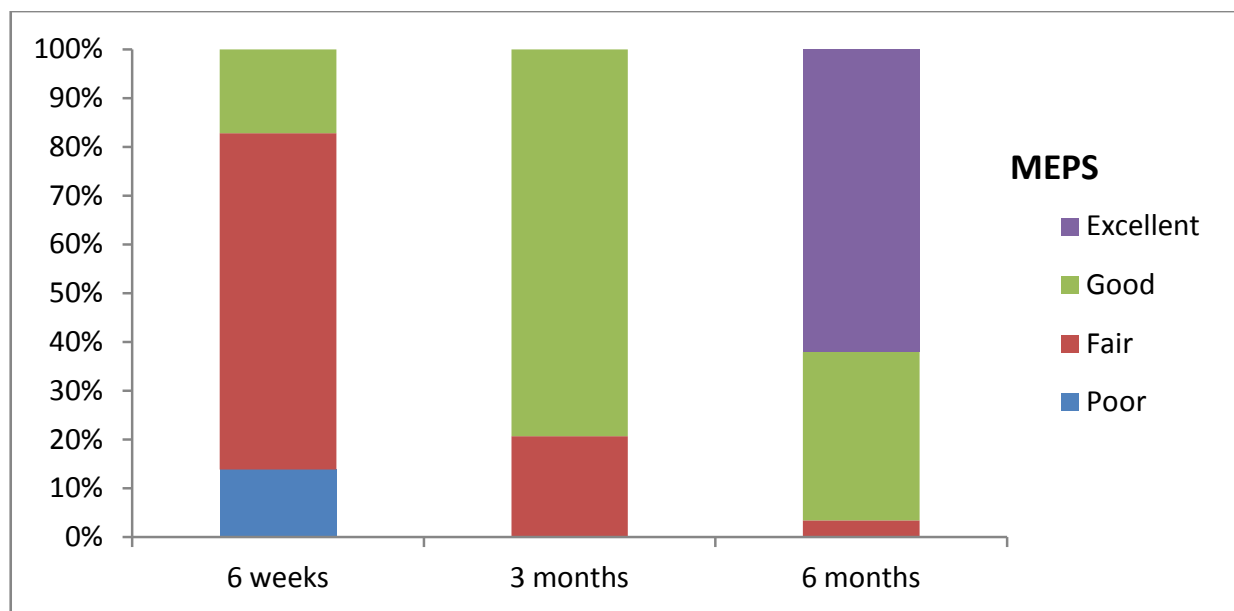

Figure 20 Improvement in Functional outcome based on Mayo Elbow performance Score from 6 weeks to 6 months (X-axis - Time since surgery, Y-axis - Percentage of total cases)

\section{Assessment of pain}

Table 5 VAS scoring of pain at 6 weeks, 3 months and 6 months

\begin{tabular}{|l|c|c|c|c|c|}
\hline \multirow{2}{*}{ Time since surgery } & \multirow{2}{*}{$\mathrm{N}$} & \multicolumn{4}{|c|}{ Pain score } \\
\cline { 3 - 6 } & & Mean & $\mathrm{SD}$ & Median & $\begin{array}{c}\text { Interquartile } \\
\text { range }\end{array}$ \\
\hline 6 weeks & 29 & 3.10 & 1.081 & 3.00 & $2.5-4.0$ \\
\hline 3 months & 29 & 1.83 & 0.966 & 1.00 & $1.0-3.0$ \\
\hline 6 monhts & 29 & 1.03 & 0.186 & 1.00 & $1.0-1.0$ \\
\hline $\mathrm{p}<0.001$ & \multicolumn{4}{|l}{}
\end{tabular}




\section{Pain score}

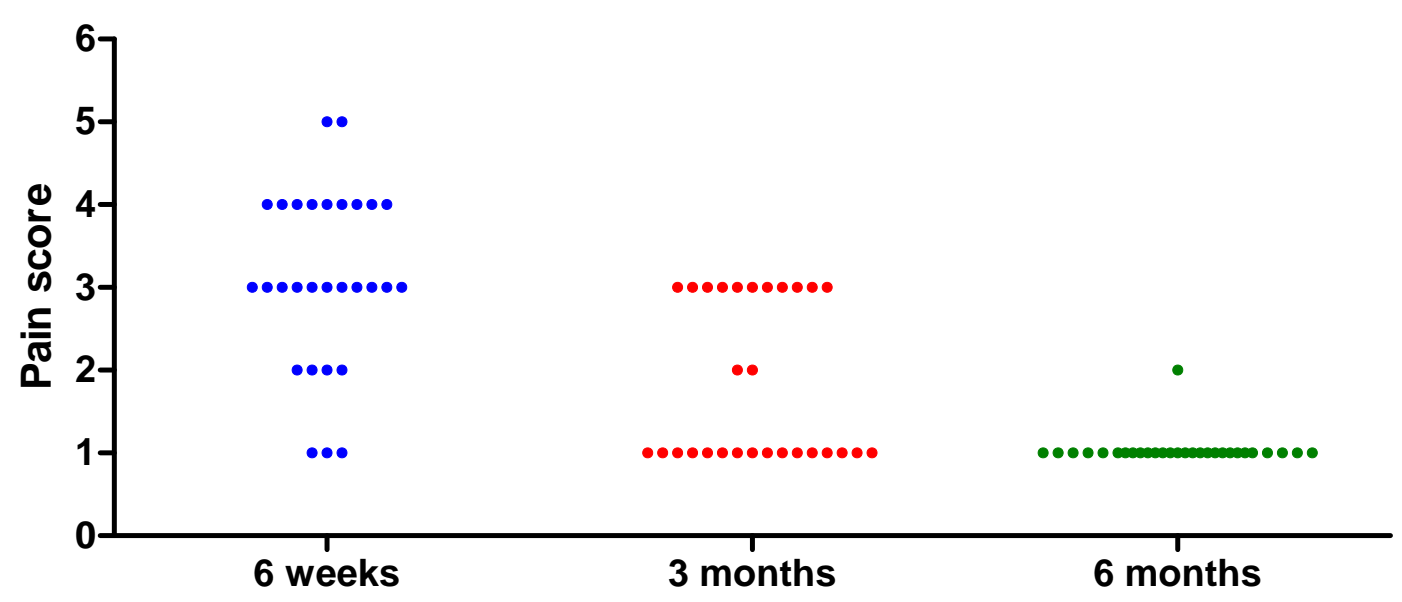

Figure 21 VAS scoring of pain at 6 weeks, 3 months and 6 months (X-axis - Time since surgery, Y-axis VAS pain score)

\section{Summary and Conclusion}

29 patients with intra-articular distal Humerus fractures treated by open reduction and internal fixation with distal Humeral locking plates were followed up for 6 months and the following conclusions were drawn:

- Majority of the patients were in the age groups $<30$ years and 61-70 years. The age of the patients ranged from 19 years to 88 years. In this study the average age was 46.9 years.

- Females were affected more.

- Majority of the patients had fall as the mode of injury.

- Left side involvement was more common, constituting $58.6 \%$ of the cases.

- The most common type noticed in this study was AO/OTA type 13-C2 constituting $20.7 \%$ of the cases.

- All the fractures were approached from the posterior aspect via an Olecranon osteotomy and fixed using anatomical distal humeral locking plates and screws.

- At 6 months, based on the Mayo Elbow Performance Score (MEPS), none had poor functional outcomes, $3.4 \%$ (1 patient) had a fair functional outcome, $34.5 \%$ (10 patients) had good outcomes and $62.1 \%$ (18 patients) had excellent functional outcomes.
- Surgical site infection developed in 2 patients $(6.5 \%$ of the population) within 6 weeks, 2 patients (6.9\%) developed hardware related complications at 6 months and myositis ossificans developed in 6 patients (20.7\% of the population).

\section{Literature review and Discussion}

The treatment of distal Humerus intra-articular fractures has greatly advanced in the past few decades due to the improved design of implants and refined surgical techniques. Presently, open reduction and internal fixation with locking plates is the most widely used method of treatment as it helps obtaining anatomical reduction, rigid fixation and early mobilization.

Miller $\mathrm{WE}^{2}$, in 1964, reviewed a series of 18 comminuted fractures of the distal end of the Humerus. He suggested that open reduction and internal fixation was the treatment of choice whenever possible and he had no regrets. Jupiter $\mathrm{JB}$ et $\mathrm{al}^{3}$, in 1985, reviewed a series of thirty-four intercondylar fractures of the distal end of the humerus that were treated by open reduction over a ten-year period. The fracture patterns were classified according to the system of Muller et al. At a mean follow-up of 5.8 years, thirteen results were rated as excellent; fourteen, as good; four, as fair; and three, as poor. 
Helfet DL, Hotchkiss $\mathrm{RN}^{4}$, in 1990, compared quantitatively three commonly used configurations of various implants used for fixation of distal humeral fractures. They concluded that, if rigid stabilization of supracondylar or bicondylar distal humeral fractures was desired, then two plate constructs, at right angles, were biomechanically optimal. Jacobson SR et $\mathrm{al}^{5}$, in 1997, assessed the bending and torsional stiffness of five commonly used multiple plate constructs. Plates were applied in three positions: medially, along the medial supracondylar column; laterally, along the lateral supracondylar column; or posterolaterally, extending distally to the capitellum. They concluded that the medial pelvic reconstruction plate combined with the posterolateral DCP provided the greatest sagittal plane stiffness, in addition to comparable frontal plane and torsional stiffness. They recommended its use in the treatment of fractures of the distal humerus.

O' Driscoll SW et $\mathrm{al}^{6}$, in 2002, conducted a study on the treatment of the smashed distal Humerus and concluded that the four goals for operative fixation must be, in order of priority, soft tissue healing without infection, restoration of diaphyseal bone stock, union between the distal fragments and the shaft, and a stable and mobile articulation. Korner $\mathrm{J}$ et $\mathrm{al}^{7}$, in 2005 , conducted a retrospective study in 45 patients treated by open reduction and internal fixation for distal humerus intra-articular fractures. A clinical and radiological follow-up was obtained after a minimum of 24 months following surgery. Functional results were evaluated according to the Mayo Elbow Score. Taking the fracture type into consideration, functional results deteriorated with degree of joint involvement.

Schwartz A et $\mathrm{al}^{8}$, in 2006, conducted a study which compared the mechanical stiffness and plate surface strains between two types of constructs for stabilization of complex distal humerus fractures. Both systems (90 deg and 180 deg constructs) demonstrated similar mechanical stiffness theoretically providing similar fracture stabilization. They also suggested that surgeon experience and preference might dictate the choice of a plate construct for this fracture configuration. McKee et $\mathrm{al}^{9}$, in 2009, had compared the outcomes and complications of TER versusplate fixation for comminuted distal humeral fractures in patients over 65 years of age. Based on both patient-based outcomes (Disabilities of the Arm, Shoulder and Hand (DASH) scores) and objective outcomes (MEPS), the authors concluded that a primary linked TER was superior to ORIF.

Huang JI et $\mathrm{al}^{10}$, in 2011, conducted a study to evaluate the functional outcomes of elderly patients after open reduction internal fixation of intra-articular distal humerus fractures. A total of 23 patients were studies of which 14 patients were available for follow up. The mean DASH score was 37.6. Bhanu Rekha ${ }^{11}$, in 2017 , conducted a study by performing bicolumnar perpendicular plating in 15 intraarticular $\mathrm{AO}$ type $\mathrm{C}$ fractures through a transolecranon approach. The average Mayo Elbow Performance Score was 85 points. They inferred that 90-90 plating was effective in intercondylar fractures of distal humerus with minimal complications.

Upon review of early literatures, we could see that open reduction and internal fixation is the primary choice of management for intra-articular fractures of the distal Humerus. In our study, we could observe that patients with higher grade of injury were observed to have poorer outcomes in various parameters like pain, swelling range of motion and MEPS. Patient compliance and Physiotherapy were equally important in achieving good results. The post-operative outcomes of our study indicated that anatomical locking plate fixation is a good option in the management of intra-articular distal Humerus fractures.

\section{References}

1. Morrey BF, An KN. The elbow and its Disorders: Functional evaluation of the elbow. 3rd edition. Philadelphia: WB Saunders; 2000. p 82. 
2. Miller WE. Comminuted fractures of the distal end of the humerus in the adult. $J$ Bone Joint Surg [Am]. 1964;46-A:644657.

3. Jupiter JB, Neff U, Holzach P, Allgöwer M. Intercondylar fractures of the humerus. An operative approach. J Bone Joint Surg Am. 1985 Feb;67(2):226-39.

4. Helfet DL, Hotchkiss RN. Internal fixation of the distal humerus: a biomechanical comparison of methods. J Orthop Trauma. 1990;4(3):260-4.

5. Jacobson SR, Glisson RR, Urbaniak JR. Comparison of distal humerus fracture fixation: a biomechanical study. J South Orthop Assoc. 1997;6:241-249.

6. O'Driscoll SW, Sanchez-Sotelo J, Torchia ME. Management of the smashed distal humerus. OrthopClin North Am. 2002;33:19-33.

7. Korner J, Lill H, Müller LP, Hessmann M, Kopf K, Goldhahn J, et al. Distal humerus fractures in elderly patients: results after open reduction and internal fixation. Osteoporos Int. 2005 Mar;16Suppl 2:S7379.

8. Schwartz A, Oka R, Odell T, Mahar A. Biomechanical comparison of two different periarticular plating systems for stabilization of complex distal humerus fractures. ClinBiomech. 2006;21:950-955.

9. McKee MD, Veillette CJH, Hall JA, Schemitsch EH, Wild LM, McCormack R, et al. A multicenter, prospective, randomized, controlled trial of open reduction--internal fixation versus total elbow arthroplasty for displaced intraarticular distal humeral fractures in elderly patients. J Shoulder Elbow Surg. 2009 Feb;18(1):3-12.

10. Huang JI, Paczas M, Hoyen HA, Vallier HA. Functional outcome after open reduction internal fixation of intra-articular fractures of the distal humerus in the elderly. J Orthop Trauma. 2011 May;25(5):259-65.

11. Bhanu Rekha. Study of intercondylar fractures of the distal humerus treated with 90-90 plating. International Journal of Orthopaedics Sciences 2017; 3(4): 31-34. 